\title{
Agricultura sustentável nos trópicos
}

\author{
ERNESTO PATER NIANI
}

Os países em desenvolvimento têm duas opções: a ciência ou a miséria.

Bernardo Houssay

\section{Agricultura: conceitos e percepção pública}

GRICUlTURA foi definida como “a arte de modificar os ecossistemas, em
termos econômicos e sem produzir danos irreversíveis" (Malavolta, 1997).
A essa definição pode-se acrescentar um componente importante: o fator

O cultivo das plantas para atender às necessidades humanas é atividade essencialmente dependente de condições edafo-climáticas, socio-econômicas e nível de conhecimentos técnicos. As técnicas agrícolas são, assim, muito diversificadas tanto ao longo do tempo quanto nas diferentes regiões do planeta. Os progressos alcançados pela agricultura, graças aos avanços científicos e tecnológicos, não têm precedentes na história da humanidade. Pela sua própria natureza a atividade agrícola perturba o meio ambiente em relação à situação silvestre. Existem exemplos de grave deterioração - do solo e do meio ambiente - provocada por atividades agrícolas inadequadas. Muito embora uma agricultura moderna, baseada em desenvolvimentos científicos, ao mesmo tempo aumente a produtividade, proteja e economize o meio ambiente, tem havido uma preocupação crescente em minimizar eventuais danos. Nos últimos anos discute-se, cada vez com mais intensidade, o que veio a ser chamado de "agricultura sustentável".

$\mathrm{Na}$ agricultura o conceito de sustentabilidade não pode ter o aspecto estático, comumente implícito no termo, pelo qual os sistemas agrícolas são considerados sustentáveis desde que a produção seja mantida nos níveis atuais. Um conceito dinâmico é mais apropriado e atende à evolução e ao desenvolvimento da sociedade. Muitas práticas agrícolas podem ter sido consideradas sustentáveis no passado, ou mesmo no presente, segundo as condições socio-econômicas, edafoclimáticas e demais características locais. Num conceito dinâmico, a sustentabilidade deve considerar as mudanças temporais nas necessidades humanas, 
especialmente relacionadas a uma população crescente, bem como uma adequada percepção da relação ambiental com a agricultura. "O objetivo de uma agricultura sustentável deve ser o de envolver o manejo eficiente dos recursos disponíveis, mantendo a produção nos níveis necessários para satisfazer às crescentes aspirações de uma também crescente população, sem degradar o meio ambiente" (FAO, 1989).

Nunca a agricultura foi tão eficiente como está sendo na atualidade e, paradoxalmente, nunca foi tão contestada como nos dias atuais. Contestações desprovidas de comprovações científicas ganham foro de verdades incontestáveis. Tal é o caso, por exemplo, da chamada "agricultura orgânica”, também chamada sustentável ou de subsistência, que na sua forma mais radical não utiliza sementes geneticamente melhoradas, fertilizantes minerais (químicos) e defensivos agrícolas; é advogada por um ambientalismo exacerbado, que vê nessa modalidade apenas benefícios e nenhum risco à saúde humana. É o que Borlaug (1996) - Prêmio Nobel da Paz de 1970 - denomina de "onda anti-tecnológica". A poesia In Balance With Nature, de John Carew, apresentada no Apêndice, retrata muito bem esse aspecto da percepção pública sobre a agricultura.

Inúmeros progressos técnico-científicos são responsáveis pela crescente eficiência agrícola que, apesar do aumento populacional, produz alimentos acima das necessidades da população mundial. Lamentavelmente, a fome existente em diversos locais do planeta é devida às imposições políticas internacionais, entre elas barreiras tarifárias, além de deficiências econômicas na distribuição de renda. A ciência, por si só, pouco pode fazer para reverter tal situação. Como o presidente François Mitterand declarou enfaticamente na conferência realizada em Washington, no Banco Mundial em setembro de 1989, “... grave perversão da economia mundial: o Sul endividado financiando o Norte opulento".

A ciência aplicada à agricultura tem conseguido não somente aumentar a produtividade dos alimentos, mas reduzir, ou mesmo eliminar, danos ao meio ambiente. Técnicas agrícolas modernas estão aumentando a produtividade e, ao mesmo tempo, melhorando a fertilidade do solo e protegendo o meio ambiente, ar, água e terra. Neste sentido, deve-se considerar, como já mencionado, que a atual geração está tomando o solo por empréstimo das gerações futuras, às quais ele deve ser devolvido com igual potencial produtivo e, se possível, melhorado.

\section{A evolução da agricultura}

Tendo surgido há cerca de um milhão e quinhentos mil anos, a espécie humana passou a maior parte desse período enfrentando toda a sorte de adversidades, incluindo uma forte competitividade com outras espécies de animais. A maior dificuldade, foi sempre garantir a adequada disponibilidade de alimentos. Por muito tempo, teve de lutar para sobreviver como caçador e colhedor de plantas. Por várias vezes esteve a ponto de enfrentar a própria extinção, conforme salienta 
o já citado Prêmio Nobel da Paz de 1970, Norman Borlaug, o Pai da Revolução Verde. Durante todo esse período, atuando essencialmente como caçador, praticamente não houve progresso social: a única preocupação era conseguir a própria sobrevivência. A população mundial nunca experimentou aumentos significativos, tendendo a se estabilizar em cerca de 10 milhões de indivíduos.

Há cerca de 10 mil anos plantas começaram a ser cultivadas e domesticadas. A iniciativa, segundo as evidências, coube às mulheres: sendo menos aptas para a caça, permaneciam cuidando de tarefas domésticas, o que lhes proporcionou maiores oportunidades de observar as plantas e desenvolver conhecimentos sobre sua utilização, propriedades e, eventualmente, sua reprodução. Assim, a agricultura é uma atividade bastante recente na história da humanidade. Tal fato pode ser facilmente visualizado ao se reproduzir o período de um milhão e quinhentos mil anos de vida da natureza humana no nosso planeta, num ano de 365 dias, no qual o homem teria surgido no dia $1^{\circ}$ de janeiro. Nessa escala, a agricultura teve inicio às 16 horas e 24 minutos do dia 29 de dezembro, ilustrando objetivamente que mais de $99 \%$ da permanência da humanidade na terra ocorreu em constante luta para encontrar alimentos para sua sobrevivência.

É interessante notar que a agricultura foi inventada pelo menos duas vezes, independentemente, no Velho e no Novo Mundo. Os dois modelos diferem entre si em vários aspectos, entre eles trabalho animal versus trabalho humano, seleção para uniformidade no Velho Mundo versus seleção para variabilidade de cores e formas nas plantas do Novo Mundo, como se observa em milho, feijões, abóboras, entre outras diferenças. Além disso, os habitantes do Novo Mundo não descobriram a roda como meio de transporte e, apesar de desenvolverem algum pastoreio em regiões da América do Norte, não houve domesticação de animais para o trabalho. Nesse curto espaço de tempo, em termos históricos, a agricultura teve uma evolução altamente significativa, como pode ser apreciado no tabela 1. O simples pastoreio ainda primitivo já significou um aumento de eficiência de dez vezes com relação à caça. Mas, sem dúvida, os subseqüentes progressos da agricultura é que foram espetaculares.

Foi a agricultura que garantiu a sobrevivência da espécie humana, eliminando definitivamente o risco de sua extinção. Possibilitou, ainda, sucessivos e contínuos aumentos da população, o que ocorre até os dias atuais. Além de garantir a sobrevivência da espécie humana, a agricultura libertou o homem da necessidade de ser nômade, permitindo o florescimento de comunidades que, com o tempo, se tornaram cidades. Destaca-se que, com o aumento da eficiência agrícola, menor número de indivíduos eram necessários para a produção de alimentos, possibilitando que grande parte da população pudesse se dedicar a outras atividades: artesanais, comerciais, artísticas, políticas, militares e religiosas. O contínuo aumento da eficiência agrícola permitiu o florescimento de sociedades cada vez mais complexas, possibilitando o crescimento de grande variedade de atividades profissionais. 
Tabela 1. Valores da produção de alimentos comparados à caça e aos vários tipos de agricultura

\begin{tabular}{|lcc|}
\hline Sistema & $\begin{array}{c}\text { Área necessária } \\
\text { (ha) }\end{array}$ & $\begin{array}{c}\mathrm{N}^{\circ} \text { de pessoas } \\
\text { alimentadas }\end{array}$ \\
\hline Caça (1) & 2500 & 1 \\
Pastoreio (2) & 250 & 1 \\
Agricultura de covas (3) & 250 & 3 \\
Agricultura de arado (4) & 250 & 750 \\
Agricultura de alta tecnologia (5) & 250 & 3600 \\
\hline
\end{tabular}

(1) Índios da América do Norte em época pré-colombiana.

(2) Índios californianos anteriores à influência européia.

(3) Índios do Leste da América do Norte antes da influência européia.

(4) Agricultura do antigo Egito.

(5) Agricultura de alta tecnologia dos Estados Unidos.

Fonte: adaptado de Stork \& Teague, 1952; Borlaug, 1972.

Mesmo após o advento da agricultura, a preocupação com a disponibilidade de alimentos sempre esteve presente, especialmente para significativas parcelas da humanidade. O espectro da fome, talvez o perigo mais temido pelos povos, tem merecido, inclusive, estudos e previsões muito pessimistas. É bem conhecida a previsão catastrófica feita em 1798 pelo reverendo Robert Malthus, ao afirmar que a fome seria inevitável. Segundo ele, enquanto a população crescia em progressão geométrica, a produção de alimentos crescia apenas em progressão aritmética, não acompanhando, assim, o aumento da população humana. Tal previsão foi corroborada nos anos 60 por Paul Ehrlich, uma Cassandra dos dias atuais, em seu livro The population bomb, publicado em 1966, no qual sustentava que nos anos 70 a América enfrentaria uma fome generalizada, quando cadáveres, vítimas da desnutrição, seriam empilhados ao longo das ruas. Graças, entretanto, aos progressos tecnológicos aplicados à agricultura, essa tenebrosa catástrofe não aconteceu, muito embora sempre tenham surgido afirmações de que tais previsões foram apenas adiadas.

Apesar de os avanços tecnológicos ocorridos em várias áreas, inclusive na agricultura, parcelas consideráveis da humanidade permaneciam em precárias condições de vida. Várias instituições foram constituídas para minorar os problemas dessas comunidades. Em 1913 foi criada a Fundação Rockefeller, com o propósito de promover melhor qualidade de vida às populações mais carentes. Durante 20 
anos a ênfase do programa foi dirigida à melhoria da saúde. Passado esse período verificou-se que não foi obtida melhora significativa na qualidade de vida da população-alvo, constatando-se que as cinco necessidades básicas para uma qualidade de vida satisfatória seriam, em ordem de prioridade, alimentação, saúde, habitação, educação e oportunidade. A importância relativa dessas necessidades poderia variar segundo o nível de desenvolvimento sócio-econômico da população. De qualquer modo, ficou evidenciada a primordial importância da alimentação, a qual, quando satisfatória, solucionaria também, ou pelo menos minoraria, problemas relacionados à saúde.

\section{Transformações das plantas domesticadas}

A enorme diversidade vegetal existente não foi totalmente utilizada para a produção de alimentos. Das cerca de 350 mil espécies de plantas conhecidas, o homem utilizou, durante toda a sua história, menos de três mil, cultivando hoje cerca de 300 espécies. Dessas, as 15 mais importantes, que contribuem com cerca de $90 \%$ da alimentação do mundo, são: arroz, trigo, milho, soja, sorgo, cevada, cana-de-açúcar, beterraba açucareira, feijão, amendoim, batatinha, batata doce, mandioca, coco e banana. Verifica-se, assim, que o homem não apenas procurou selecionar as melhores plantas de cada espécie, mas, também, gradualmente foi se concentrando em menor número de espécies, ficando com as que apresentavam maior potencial produtivo. Isso representa, sem dúvida, uma redução da biodiversidade genética utilizada.

Durante esses 10 mil anos de agricultura, as comunidades agrícolas foram procedendo à domesticação das plantas, transformando-as de silvestres, em plantas domesticadas. Em muitos casos, a transformação foi de tal magnitude que essas plantas perderam a capacidade de sobreviver por si mesmas na natureza, dependendo do cultivo pelo homem. Em inúmeras espécies as mudanças foram tão profundas, que dificilmente se poderá perceber quais foram os seus ancestrais silvestres. Por esse motivo, têm sido objeto de intensos estudos sobre a origem e domesticação das plantas cultivadas.

Inúmeras características das plantas silvestres foram alteradas durante a domesticação, destacando-se:

- perda da dispersão natural das sementes, fazendo com que os grãos, por exemplo, permanecessem presos à espiga, facilitando a colheita;

- perda da dormência das sementes, fazendo com que todas germinem ao mesmo tempo com uniformidade;

- ausência ou redução de substâncias amargas e tóxicas;

- ausência ou redução de mecanismos de proteção (espinhos, aristas etc.);

- mudança da reprodução alogâmica (cruzamentos) para a autogâmica (autofecundação); 
- mudança do ciclo de vida perene para anual, o que aumentou a produtividade por área;

- mudança de plantas dióicas (plantas masculinas e plantas femininas) para monóicas, ou

- hermafroditas (os dois sexos na mesma planta) evitando, assim, plantas masculinas improdutivas;

- aumento do tamanho dos frutos, dos grãos e da produtividade em geral, além de inúmeros caracteres como qualidade, sabor etc.

Ressalta-se que todas essas mudanças foram conseguidas apenas pela seleção empírica, realizada pelas pequenas comunidades agrícolas e continuada por centenas ou milhares de gerações, que não detinham os conhecimentos de genética hoje disponíveis sobre a herança dos caracteres dos seres vivos. Tal fato atesta o enorme potencial da variabilidade genética existente nas espécies, bem como a atenção e dedicação dadas pelas primeiras comunidades de agricultores às suas plantas cultivadas. Certamente esse aspecto se deveu à sua sobrevivência ter passado a depender cada vez mais da capacidade de produção de alimentos das plantas cultivadas.

Destaca-se ainda que quase todas as plantas cultivadas atualmente foram domesticadas pelos povos antigos. O homem moderno já recebeu de seus antepassados as plantas domesticadas, praticamente sem acrescentar espécies novas. Com os avanços dos conhecimentos científicos, a humanidade passou apenas a dar continuidade às transformações feitas anteriormente, utilizando cada vez com maior eficiência novas tecnologias decorrentes dos progressos científicos.

\section{Vulnerabilidade das plantas domesticadas}

Muito embora a domesticação das plantas tenha garantido a sobrevivência da espécie humana e a sua expansão, trouxe, entretanto, alguns inconvenientes $\mathrm{O}$ mais sério foi a sua vulnerabilidade quanto às enfermidades causadas por microorganismos, em especial fungos e bactérias.

No estado selvagem as plantas ocorriam dispersas na natureza em meio a outras espécies, o que as tornavam relativamente protegidas, pois, embora algumas sofressem infestações, muitas preservavam-se e permaneciam sadias. Além disso, na natureza a variabilidade genética era muito ampla, fator adicional para a ocorrência de plantas geneticamente resistentes às enfermidades. Sendo selecionadas artificialmente por muitas gerações, na domesticação as plantas tornaram-se cada vez mais uniformes. Como conseqüência, passaram a ser mais vulneráveis aos ataques dos agentes infecciosos. Além disso, ao contrário do que ocorria na natureza, eram cultivadas de forma mais compacta, adensadas, favorecendo ainda mais a susceptibilidade às enfermidades. 
Desde os tempos bíblicos encontram-se relatos sobre desastres na produção de alimentos em conseqüência de pragas e enfermidades. Na Roma antiga, Plínio considerava "a ferrugem do trigo a maior praga das lavouras". Talvez o exemplo mais dramático, tenha sido a epidemia da requeima da batatinha, que apareceu de 1830 a 1840 no Oeste da Europa e Nordeste dos Estados Unidos, atingindo proporções catastróficas em 1845 na Irlanda. Esse país tinha a batatinha como base da sua alimentação; a requeima foi tão violenta que matou de fome cerca de um milhão de pessoas, tendo outro milhão emigrado para os Estados Unidos. Posteriormente o agente infeccioso foi identificado como um fungo, que recebeu o nome de Phytophthera infestans (do grego Phyto = planta e phthera = destruidor). Essa mesma enfermidade ocorreu nas lavouras germânicas por ocasião da Primeira Guerra Mundial, o que pode ter contribuído para apressar o seu término.

Esses exemplos ilustram grandes desastres agrícolas, com ocorrência mais freqüente no passado, antes de estarem disponíveis conhecimentos científicos mais avançados. Ao longo do tempo, com os avanços científicos, os pesquisadores procuraram incorporar à agricultura novas tecnologias para tornar as plantas cada vez mais eficientes na produção de alimentos, minimizando a sua vulnerabilidade às condições adversas, de tal modo que se tornasse possível utilizar racionalmente os recursos naturais disponíveis, preservando, ao mesmo tempo, áreas para a vida silvestre.

Salienta-se ainda que a agricultura não deve ser comparada com a mineração, que utiliza o solo até o esgotamento da sua fertilidade. O solo na agricultura, como mencionado, é algo que se toma emprestado das gerações futuras, às quais deve ser entregue preferivelmente com sua fertilidade melhorada. Neste particular, o Brasil tem dado exemplo notável ao conseguir tornar férteis os solos dos cerrados, anteriormente considerados impróprios para a agricultura. A tecnologia aqui desenvolvida está revolucionando a agricultura tropical, com perspectivas de ser usada em outras regiões semelhantes do globo.

\section{Progressos tecno-científicos relacionados à maior eficiência agrícola}

Muito embora certos conhecimentos relativos ao cultivo das plantas - noções de nutrição mineral, reprodução sexual, entre outras técnicas agrícolas - já estivessem disponíveis no século XIX, a agricultura como ciência aplicada foi desenvolvida no século XX. Sendo ciência aplicada, é natural que seus pesquisadores procurem utilizar tanto quanto possível os progressos da ciência básica para melhorar a eficiência agrícola. Os seguintes marcos são pertinentes:

- o início da indústria de fertilizantes, por volta de 1840, com a produção de superfosfato simples por Lawes, na Inglaterra, logo depois que Liebig na Alemanha mostrou que as plantas são alimentadas por ar, água e um conjunto de minerais retirados do solo; 
- a herança genética mendeliana, pelo abade Gregorio Mendel em 1865, e a sua redescoberta em 1900 por De Vries, Correns e Tschermack;

- a heterose ou vigor de híbrido em milho (East, 1908; Shull, 1909), depois estendida a outras culturas, o que pode ser considerado como a maior contribuição do século XX para a agricultura;

- a contribuição de Thomas Hunt Morgan, por volta de 1910, mostrando o papel dos cromosomos na herança genética;

- a base genética de caracteres complexos, chamados de quantitativos, primeiramente estudados por Nilsson-Ehle na primeira década de 1900, e com mais profundidade por Fisher (1918), que conduziu ao desenvolvimento de métodos de melhoramento mais eficientes;

- o desenvolvimento de métodos estatísticos por Fisher em 1917 (Fisher, 1936), que conduziu ao desenvolvimento de delineamentos experimentais, aumentando sensivelmente a precisão das avaliações de campo;

- o efeito das radiações ionisantes para a produção artifical de novas mutações gênicas por J.H. Muller e L.J. Stadler por volta de 1930;

- o conhecimento de que a resistência e a suscetibilidade das plantas a enfermidades causadas por fungos são controladas por genes e, em seqüência, a teoria de Flor (1955), estabelecendo que para cada gene de virulência num fungo existe um correspondente gene de resistência na planta hospedeira;

- vários métodos de melhoramento de plantas, entre os quais obtenção e avaliação de linhagens para a produção de milho híbrido, esquemas de seleção recorrente (tanto intra quanto inter-populacional) métodos para melhoramento de espécies autogâmicas e de reprodução assexuada;

- as descobertas relativas ao material genético - DNA (ácido desoxirribonucleico) - levaram ao desenvolvimento da genética molecular e à produção de plantas transgênicas;

- o desenvolvimento do conceito de Manejo Integrado de Pragas (MIP), pelo qual são controladas com uma combinação de técnicas: pesticidas, resistência genética, controle ambiental, práticas agrícolas, controle biológico;

- o desenvolvimento da técnica do plantio direto e sua significativa contribuição para o controle da erosão e dos demais aspectos de proteção ambiental (ar e água limpos).

Graças ao emprego das tecnologias melhoradas disponíveis, tem sido verificado no mundo, em geral, aumento na produtividade agrícola por unidade de área. Estima-se que atualmente no mundo todo sejam cultivados cerca de 18 milhões de $\mathrm{km}^{2}$, área equivalente à da América do Sul. Se a produtividade agrícola fosse igual à de 1950, seriam necessários 48 milhões de $\mathrm{km}^{2}$ de área cultivada (Avery, 1994). Desde 1968 a Suécia voltou a plantar florestas em mais de cinco 
milhões de hectares, antes usados na agricultura, sem diminuição da produção agrícola (FAO, 1969; 1991). O Chile, sem aumentar sua área agrícola, tem conseguido alimentar uma população que cresce $1,7 \%$ ao ano, aumentando, ao mesmo tempo, a sua exportação de frutas e hortaliças. Por outro lado o Equador, devido à sua agricultura de baixa tecnologia, tem sido forçado a expandir a área agricultável, derrubando as suas florestas a razão de $2 \%$ ao ano (Avery, 1994).

Inúmeros estudos indicam a necessidade de aumentar a produção de fibras e alimentos para satisfazer às necessidades de uma crescente população mundial. A área agricultável per capita vem sendo significativamente reduzida, desde cerca de 1 ha em 1960 a 0,5 em 2000, projetando-se 0,3 para 2040 (Krattiger, 1998). Nem todos os países estão nas mesmas condições, pois vários deles, como o Brasil, ainda possuem grande quantidade de terra adequada para agricultura. Mesmo nessas situações, o emprego racional das técnicas disponíveis para melhorar a eficiência da agricultura contribuirá para proteger as áreas dedicadas à vida selvagem, ajudando a melhorar o meio ambiente, o que corresponde ao objetivo sustentável.

\section{Agricultura tropical e agricultura de clima temperado}

Os países de clima temperado, em especial os do hemisfério Norte globalmente chamados de Primeiro Mundo, são bem mais desenvolvidos do que os países tropicais, em geral do hemisfério Sul, especialmente em termos tecnológicos. É natural, assim, que as regiões de clima temperado sejam tomadas como referência quando se deseja estimar o nível de desenvolvimento tecnológico dos países tropicais.

No caso da agricultura, entretanto, essa comparação não é adequada, uma vez que as condições climáticas, entre outros fatores, são marcadamente diferentes. A pluviosidade, por exemplo, ocupa lugar de destaque entre os fatores que afetam a agricultura. Na tabela 2 são apresentadas as médias pluviométricas relativas ao período de 1917 a 1985 entre um local de clima temperado (Ames, Iowa, USA, $42^{\circ} \mathrm{N}, 93^{\circ} \mathrm{W}$ ) e outro subtropical (Piracicaba, SP, Brasil, $22^{\circ} \mathrm{S}, 47^{\circ} \mathrm{W}$ ), para os meses de julho e agosto em Ames, e dezembro e janeiro em Piracicaba, que são os meses mais importantes para os cultivos de verão, por exemplo, do milho. Nas figuras 1 e 2 podem ser visualizadas as variações anuais relativas a esses meses nos dois locais, verificando-se a grande variabilidade em Piracicaba, e a relativa estabilidade em Ames.

As regiões temperadas e tropicais diferem ainda em outras características que influem na atividade agrícola ou nela interferem. Na tabela 3 são ilustradas algumas diferenças entre as duas regiões, verificando-se que nos trópicos as condições em geral são mais adversas, os problemas mais numerosos e mais complexos, além de os fatores socio-econômicos e de infra-estrutura serem mais desfavoráveis do que os das regiões temperadas. As incertezas e imprevisibilidade 
das condições climáticas, a sua variabilidade entre anos e entre locais constituem enormes desafios a serem enfrentados por pesquisadores para desenvolver cultivares melhoradas e demais técnicas agronômicas que possam fazer face a essas condições adversas.

Tabela 2. Comparação da pluviosidade entre um local de clima temperado (1) e outro subtropical (2) - Médias entre 1917 e 1985

\begin{tabular}{rccccc}
\hline \multicolumn{2}{c}{ Ames, Iowa, USA } & \multicolumn{3}{c}{ Piracicaba, SP, Brasil } \\
\hline Período & $\begin{array}{c}\text { Médias } \\
(\mathrm{mm})\end{array}$ & $\begin{array}{c}\text { Desvio padrão } \\
(\mathrm{mm})\end{array}$ & Período & $\begin{array}{c}\text { Médias } \\
(\mathrm{mm})\end{array}$ & $\begin{array}{c}\text { Desvio padrão } \\
(\mathrm{mm})\end{array}$ \\
$\begin{array}{c}\text { Pré-plantio } \\
\text { (set./jun. })\end{array}$ & 618,5 & 117,96 & & & \\
$\begin{array}{c}\text { Julho } \\
\text { Agosto }\end{array}$ & 92,6 & 35,51 & Dez. & 218,9 & 75,88 \\
\hline
\end{tabular}

(1) Ames, Iowa, US, $42^{\circ} \mathrm{N}, 93^{\circ} \mathrm{W}$

(2) Piracicaba, SP, Brasil, $22^{\circ} \mathrm{S}, 47^{\circ} \mathrm{W}$

Fonte: Paterniani, 1990.

Tabela 3. Comparação entre clima temperado e tropical para a cultura do milho

\begin{tabular}{|c|c|c|}
\hline Características & Temperado & Tropical \\
\hline \multicolumn{3}{|c|}{ Condições de crescimento } \\
\hline Variação climática anual & Relativamente estável & Variável, não-previsível \\
\hline Variação pluviométrica anual & Relativamente uniforme & Variável, não previsível \\
\hline Chuvas entre locais & Relativamente uniforme & Variável, não-previsível \\
\hline Fotoperíodo & Dias longos & Dias curtos \\
\hline Temperatura noturna & Frescas & Mais quentes \\
\hline Condições de solo & Geralmente favoráveis & Freqüentemente adversas \\
\hline Período de semeadura & Restrito (poucos dias) & Amplo (vários meses) \\
\hline Período vegetativo & Bem definido & Variável amplo \\
\hline Dificuldade de germinação & Solos frios e fungos & Insetos de solo \\
\hline Infestação de ervas más & Mediana & Alta \\
\hline Insetos de grãos armazenados & Baixa infestação & $\begin{array}{l}\text { Alta infestação, } \\
\text { começando no campo }\end{array}$ \\
\hline \multicolumn{3}{|c|}{ Tipos de milho } \\
\hline Ciclo vegetativo & $\begin{array}{l}\text { Uniforme, adaptado } \\
\text { à estação de crescimento } \\
\text { e sócio-econômicas }\end{array}$ & $\begin{array}{l}\text { Variável, para adaptações } \\
\text { a condições climáticas }\end{array}$ \\
\hline Altura da planta & Mediana a baixa & Geralmente alta \\
\hline \multicolumn{3}{|c|}{ Infra-estrutura } \\
\hline Distância entre localidades & $\begin{array}{l}\text { Curtas e satisfatórias } \\
\text { longas }\end{array}$ & Freqüentemente muito \\
\hline Transporte e comunicação & Geralmente satisfatórias & $\begin{array}{l}\text { Freqüentemente } \\
\text { não-satisfatórias }\end{array}$ \\
\hline Número de pesquisadores & Adequado & Insuficiente \\
\hline
\end{tabular}

Fonte: Paterniani, 1990. 


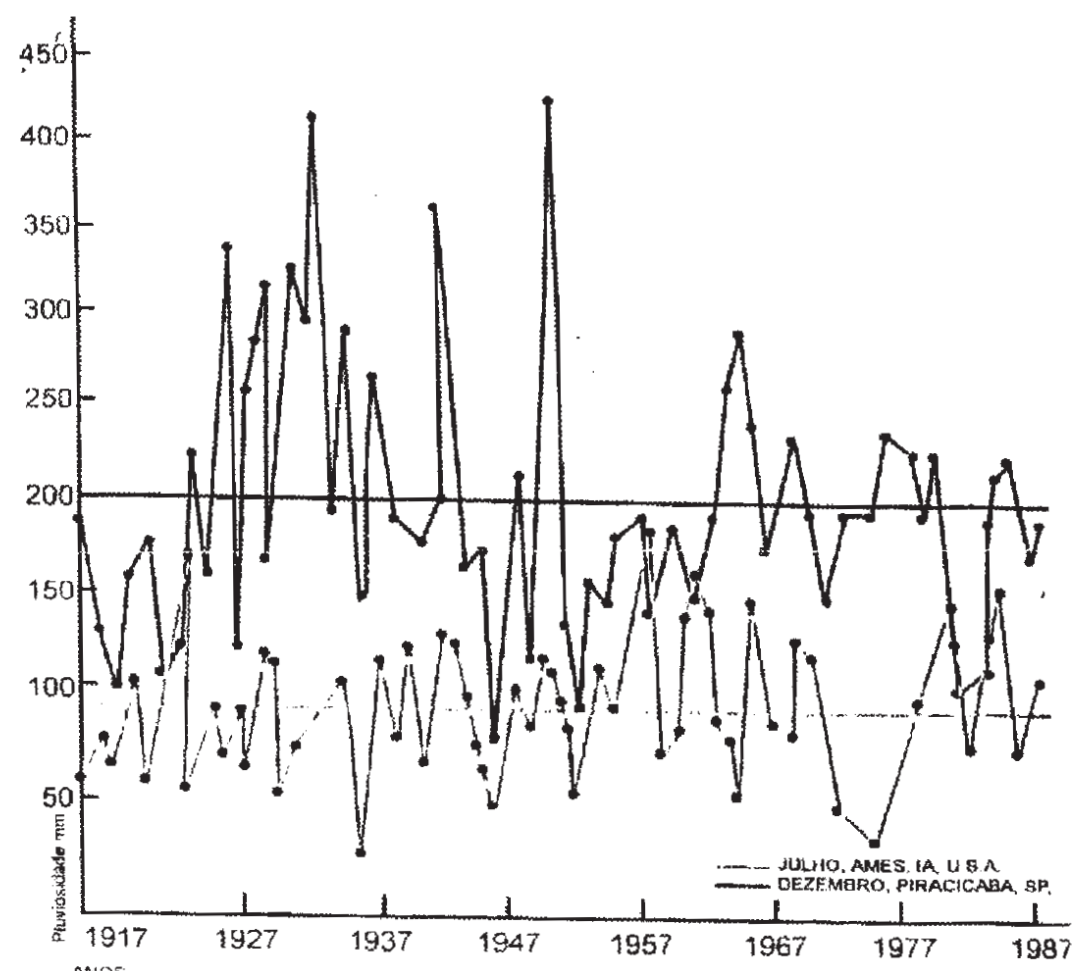

Fig. l. Variações da quantidade de chuva para o mês de julho (Ames, Iowa, USA) e dezembro (Piracicaba, SP, Brasil). (Paterniani, 1990)

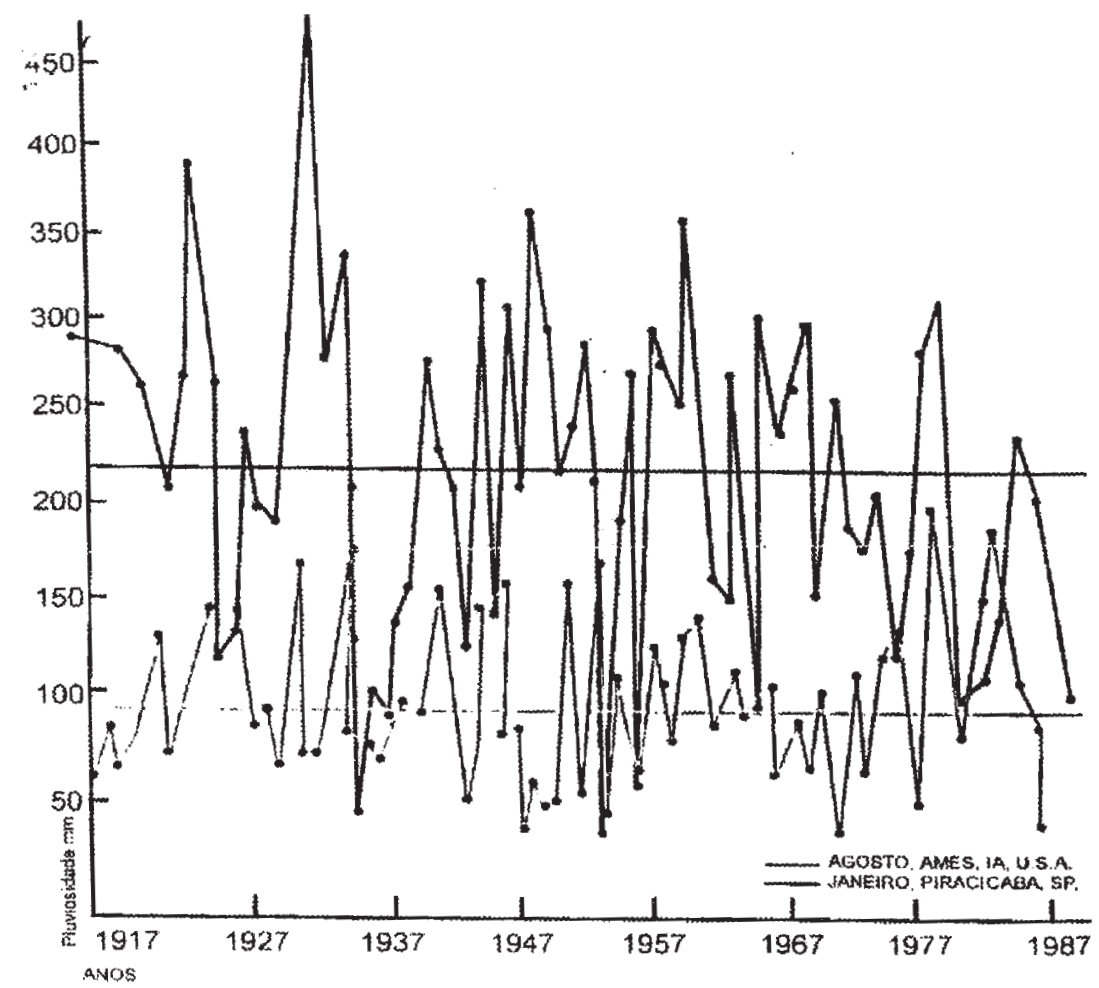

Fig. 2. Variações da quantidade de chuva para o mês de agosto (Ames, Iowa, USA) e janeiro (Piracicaba, SP, Brasil). (Paterniani, 1990) 
Outra diferença digna de nota refere-se ao fotoperíodo. Enquanto nos climas temperados os dias são longos, cerca de 15-16 horas de luz no verão, nos trópicos os dias são bem mais curtos, aproximadamente 13 horas. Nessas condições, nos climas temperados a fotossíntese processa-se por maior período, fixando maior quantidade de $\mathrm{CO}^{2}$ do que é fixada nos trópicos. Além disso, as noites mais curtas e frescas nas regiões temperadas correspondem a um menor período de respiração, no qual parte do $\mathrm{CO}^{2}$ fixado durante o dia é perdido. Nos trópicos, ao contrário, as noites são mais longas e mais quentes, aumentando a intensidade da respiração e, por conseqüência, maior quantidade de $\mathrm{CO}^{2}$ é perdida. Além disso, os solos das regiões temperadas são menos ácidos, mais férteis, têm reservas de minerais primários, argilas mais ativas e são menos sujeitos à lixiviação e à erosão.

\section{Exemplos de sucessos da agricultura brasileira}

As plantas são especialmente dependentes das condições climáticas, além do solo. As espécies e suas variedades não ocorrem em todas as condições, mas têm suas adaptações climáticas específicas. É em razão dessas diferenças, ao contrário do que ocorre com produtos industriais (carros, eletrodomésticos, por exemplo), que podem ser adequadamente utilizados em quaisquer regiões, no caso da agricultura, as cultivares, os processos e as tecnologias adequados para as regiões temperadas são inapropriados e não-adaptáveis às condições tropicais. Tal aspecto torna imperativo que todas essas tecnologias devam ser necessariamente desenvolvidas nas condições locais onde serão utilizadas, o que aumenta ainda mais a importância da pesquisa científica para a agricultura brasileira.

Assim, a comparação adequada para a agricultura deve ser feita entre regiões ecologicamente semelhantes. Neste particular, é notório que o Brasil conta com uma agricultura mais desenvolvida do que outras regiões tropicais do globo. Uma análise mais abrangente dos resultados da pesquisa científica na agricultura brasileira pode ser apreciada em recente publicação da Embrapa (2000). Na área do melhoramento genético, os seguintes exemplos relatados por Vencovsky \& Ramalho (2000), podem ser citados.

\section{Café}

A partir do melhoramento genético iniciado no Instituto Agronômico de Campinas, em 1933, a variedade Mundo Novo produz $2340 \mathrm{~kg} / \mathrm{ha}$, correspondendo a $314 \%$ da produção da Arábica que é de $745 \mathrm{~kg} /$ ha (Carvalho \& Fazuoli, 1993). Subseqüentemente, novas variedades têm sido obtidas com maior rendimento, associadas a importantes características, como a resistência à ferrugem (Hemileya vastatrix).

\section{Milho}

O melhoramento genético do milho tem alcançado progresso contínuo ao longo dos anos, como pode ser verificado pelos incrementos anuais de produção 
de grãos em $\mathrm{kg} / \mathrm{ha} /$ ano relatados por vários autores: 60, no período de 1946 a 1986 (Paterniani, 1990); 72 a 109, de 1964 a 1983 (Vencovsky et al., 1986); 31 a 51, de 1970 a 1990 (Araújo, 1995); 123, de 1964 a 1993). Além de o aumento da produtividade, importantes caracteres agronômicos, como resistência a enfermidades, plantas mais compactas, resistência ao acamamento, foram incorporados no melhoramento. Nos últimos 15 anos vem alcançando sucesso o cultivo de milho fora da estação usual de verão. Trata-se do plantio "safrinha" a partir de fevereiro, para o que novas cultivares foram desenvolvidas.

\section{Soja}

Até 1970 o Brasil não tinha expressão no plantio de soja, pois representava apenas $2 \%$ da produção mundial, tornando-se hoje produtor de $20 \%$ desse tipo de grão. Em 1961 a produtividade era de $1127 \mathrm{~kg} / \mathrm{ha}$, chegando em 1998 a $2237 \mathrm{~kg} / \mathrm{ha}$, correspondendo a um aumento anual de $31,6 \mathrm{~kg} / \mathrm{ha} / \mathrm{ano}$, ou seja, um ganho de $1200 \mathrm{~kg} / \mathrm{ha}$ em 38 anos de pesquisa (Vencovsky \& Ramalho, 2000).

\section{Arroz}

Soares \& Ramalho (1993) e Rangel et al. (1996) relataram que no período de 1974 a 1996 obteve-se um ganho de $33 \mathrm{~kg} / \mathrm{ha} /$ ano para o arroz de sequeiro e de $44 \mathrm{~kg} / \mathrm{ha} /$ ano para o arroz irrigado.

\section{Feijão}

A produtividade do feijão tem sido aumentada graças às técnicas adequadas de cultivo e ao melhoramento genético. Avaliações procedidas durante 20 anos indicaram um progresso da ordem de $42,6 \mathrm{~kg} / \mathrm{ha} / \mathrm{ano}$, tendo sido o progresso genético de cerca de 14,5 kg/ha/ano (Abreu et al., 1994).

\section{Frutas de clima temperado}

O melhoramento genético conseguiu produzir variedades de frutas de clima temperado, como maçã, pera, pêssego, nectarina, ameixa, figo, moranguinho e nozes européias. De especial significado foram os sucessos obtidos com maçã, pêssego, pera e ameixa, originalmente não-adaptáveis às condições climáticas do Brasil, uma vez que requerem longos períodos de baixas temperaturas para a indução do florescimento. A produção de 16 mil ton de maçãs em 1977 para 495 mil ton em 1995, com um ganho de 0,6 ton/ha/ano, tornou o Brasil, inclusive, exportador para mercados muito exigentes.

\section{Eucalipto}

Introduzido da Austrália na segunda década do século XX, o eucalipto tornou-se a madeira mais importante para uso generalizado. Seleção genética conduzida tanto por instituições públicas quanto privadas, resultou em significativo progresso, como pode ser constatado pelo aumento de sua produtividade, 
de $20 \mathrm{~m}^{3}$ /ha/ano em 1960 para $40 \mathrm{~m}^{3} / \mathrm{ha}$ /ano em 1998. Cerca de $50 \%$ desse incremento é atribuído ao melhoramento genético (Ferreira \& Santos, 1997).

Inúmeras outras espécies têm sido melhoradas, destacando-se hortaliças, em especial com adaptação ao verão, e citrus, sendo o Brasil líder mundial na exportação de suco de laranja.

\section{Manejo integrado de pragas - MIP}

O controle de pragas tem passado por várias fases e, em função das pesquisas e conhecimentos obtidos, emprega-se atualmente um sistema racional denominado manejo integrado de pragas, que compreende um equilíbrio de diferentes técnicas: proteção do meio ambiente, controle biológico, controle químico, resistência genética das plantas e práticas cultivares. Dependendo da intensidade da infestação e das condições locais, entre outros fatores, são empregadas as técnicas mais apropriadas ou suas combinações.

Na cana-de-açúcar, a broca (Diatraea saccharalis)é a praga mais freqüente. No passado moscas nativas, como Metagonistylum minense e Paratheresia claripalpis, foram usadas para combater a praga. Um parasita introduzido de Trinidad Tobago, Cortesia flavipes, mostrou-se muito mais eficiente, sendo atualmente largamente usado. Nos anos 70, com 10\% de infestação, havia uma perda anual de US\$ 100 milhões. Hoje, graças aos novos parasitas, a infestação é da ordem de $2 \%$, apesar de o aumento da área cultivada, duas vezes maior (Macedo et al., 1993).

Na soja, a lagarta Anticarsia gemmatalis é eficientemente controlada pelo Baculovirus anticarsia. Nas mais diversas culturas, como pastagens, trigo, tomate, algodão, citrus, as pragas estão sendo controladas por combinações de técnicas representando seu manejo integrado.

\section{Nutrição de plantas e fertilização}

O desenvolvimento satisfatório das plantas somente pode ser obtido com um suprimento adequado de nutrientes. Progressos no conhecimento das necessidades nutricionais das plantas têm resultado em significativos aumentos de produtividade no Brasil. Malavolta (2000) apresentou uma revisão da nutrição de plantas e fertilização adequada para as culturas mais importantes do Brasil, juntamente com as necessidades de correção de solos pobres, como os "cerrados". Por essa revisão, as seguintes afirmativas são pertinentes: "No período 19501997, o consumo de adubos minerais no Brasil aumentou 69 vezes. O uso por hectare multiplicado por 10 e per capita cresceu oito vezes. Entretanto, o consumo é ainda $1 / 5$ do recomendado. A produtividade agregada de 16 culturas entre 1970 e 1995 passou de 1450 para $2804 \mathrm{~kg}$ por hectare, o que permitiu a economia de 45 milhões de hectares de terra do Cerrado, da Amazônia, do Pantanal matogrossense ou das planícies do Sul. Estima-se a contribuição do adubo entre $11 \mathrm{e}$ 
15 milhões de hectares, o que corresponde a US\$ 2 a US\$ 3 bilhões, considerandose o valor da terra. Esses números desmentem mitos divulgados pelos meios de comunicação e pelas ONGs, segundo os quais os adubos minerais contaminam os alimentos e poluem o ar, a água e o solo. Tais alegações não têm apoio na pesquisa brasileira ou alienígena”.

\section{Plantio diveto}

O plantio convencional, envolvendo aração, gradagem e demais atividades de movimentos de solo, conduz a uma série de danos ao meio ambiente, salientando-se o elevado índice de erosão e conseqüente assoreamento das represas hidrelétricas, empobrecimento e esterilização do solo, sua compactação e demais inconvenientes. Por outro lado, o plantio direto na palha, como o próprio nome indica, dispensa as atividades de movimento do solo, semeando-se nele diretamente, sem aração ou gradagem. Resumidamente, é feito apenas um pequeno sulco para comportar a semente. Após a colheita, os restos da cultura são roçados, permanecendo no solo.

Planta-se ainda na entre-safra uma cultura para produção de matéria orgânica, que também é deixada sobre o solo. Com os sucessivos anos agrícolas há um aumento da matéria orgânica, quase total ausência de erosão e demais benefícios decorrentes. No próximo ano agrícola a semente é colocada no pequeno sulco no solo coberto de palha. O plantio direto na palha assemelha-se à condição da floresta, onde a quantidade de matéria orgânica é elevada e não há movimento de solo. O plantio direto na palha corresponde, assim, a uma autêntica agricultura orgânica.

Na tabela 4 é feita uma comparação de perda de água, solo e nutrientes entre o plantio convencional e o plantio direto na palha. No quadro 3 são ilustradas as principais vantagens desse sistema agrícola.

Tabela 2. Perdas de água, solo e nutrientes em latossolo roxo em função dos sistemas de cultivo

\begin{tabular}{lrrrrrrr}
\hline Sistema & $\begin{array}{c}\text { Água } \\
\mathrm{m}^{3} / \mathrm{ha}\end{array}$ & $\begin{array}{c}\text { Solo } \\
\mathrm{t} / \mathrm{ha}\end{array}$ & $\mathrm{N}$ & $\mathrm{P}_{2} \mathrm{O}_{5}$ & $\begin{array}{l}\mathrm{K}_{2} \mathrm{O} \\
\mathrm{kg} / \mathrm{ha}\end{array}$ & $\mathrm{CaO}$ & $\mathrm{MgO}$ \\
\hline P.D. & 33 & 2,2 & 3,6 & 0,2 & 0,8 & $\begin{array}{r}3,7 \\
83\end{array}$ & $\begin{array}{r}0,8 \\
\text { P.C. }\end{array}$ \\
\hline
\end{tabular}

P.D. = Plantio direto.

P.C. $=$ Plantio Convencional.

Fonte: Fundação ABC, Ponta Grossa (PR). 
Tabela 5. Benefícios do plantio direto na palha

\begin{tabular}{|l|}
\hline Evita a erosão do solo \\
Evita a compactação do solo \\
Maior disponibilidade de água \\
Melhor aproveitamento da água \\
Melhora a capacidade tampão do solo \\
Aumenta matéria orgânica no solo \\
Aumenta a quantidade de minhocas e microrganismos \\
Aumenta a disponibilidade de N, P e K \\
Reduz a toxicidade do Al, Mn, Cd e pesticidas \\
Permite semeaduras mais oportunas \\
Proporciona mais tempo para outras atividades \\
Menores custos de produção \\
Contribui para o seqüestro de carbono \\
Diminui assoreamento nas represas das hidrelétricas
\end{tabular}

A região dos Campos Gerais, no Paraná, é um centro de excelência na pesquisa e no emprego do plantio direto que vêm se expandindo continuamente. Estima-se que atualmente 12 milhões de ha estejam sob plantio direto no Brasil.

\section{A perspectiva da biotecnologia e as plantas transgênicas}

O melhoramento de plantas sempre depende da variabilidade possível de ser empregada. No melhoramento convencional apenas é possível a utilização da variabilidade presente dentro da espécie a ser melhorada. A partir do conhecimento da estrutura do material genético DNA (ácido desoxirribonucleico), da decifração do código genético e dos subseqüentes desenvolvimentos da genética molecular foi possível proceder à manipulação dos genes e às suas transferências entre espécies. As plantas assim obtidas são chamadas de transgênicas, e também as resultantes de organismos geneticamente modificados (OGM), embora todas as plantas melhoradas sejam também resultados de modificações gênicas. O melhoramento de plantas sendo considerado como ciência aplicada, é natural o emprego da nova tecnologia para a obtenção de novas variedades melhoradas. A transgenia amplia consideravelmente a variabilidade disponível, pois pode utilizar a variabilidade existente em todos os seres vivos. Assim, quando uma característica desejável não é encontrada no genoma da espécie de interesse, mas o gene responsável por essa característica é identificado em outra espécie, tal gene pode ser transferido para a espécie a ser melhorada.

A biotecnologia é hoje essencialmente uma ferramenta a mais à disposição do pesquisador, que possibilita a obtenção de plantas geneticamente modificadas 
de maneira mais previsível. Isso é possível porque o código genético é universal, ou seja, é o mesmo para todos os seres vivos. Resumidamente, pode-se dizer que um gene, ao ser transferido para o genoma de outra espécie, vai determinar nessa espécie a mesma característica que determinava na espécie doadora. É por esse motivo que o gene responsável pela produção de insulina humana, ao ser transferido para a bactéria Escherichia coli torna essa bactéria produtora de insulina humana. De 1986 a 1997, 45 países aprovaram plantios experimentais de plantas transgênicas (James, 1997). O Brasil não figura nessa relação, uma vez que tais experimentos só se iniciaram no país a partir de 1998, com a criação da Comissão Técnica Nacional de Biossegurança (CTNBio).

James (2000) relata que, atualmente, 13 países cultivam plantas transgênicas. Em 2000 foram cultivados 44,2 milhões de hectares de plantas transgênicas, sendo $85 \%$ desse total em países desenvolvidos, com destaque para Estados Unidos e Canadá. Entre os países em desenvolvimento maiores produtores de transgênicos, cita a Argentina e a China. Dentre as principais culturas transgênicas estão a soja, o milho e o algodão. Inúmeros países, incluindo o Brasil, conduzem pesquisas destinadas à avaliação de plantas transgênicas e à obtenção de novas variedades transgênicas. Entre as espécies pesquisadas destacam-se milho, soja, algodão, arroz, feijão, cana-de-açúcar, batata, mamão, eucalipto e tomate. Em outros países são incluídos, ainda, melão, abóbora, fumo, beterraba açucareira, trigo, alfafa, pepino, girassol, alface, canola, maçã, amendoim dentre outras. Das características incorporadas destacam-se tolerância a herbicidas, resistência a insetos, resistência a vírus, qualidade do produto, resistência a fungos, além de outras características agronômicas.

Entre as características mais incorporadas nas plantas transgênicas destacam-se a resistência a herbicidas e a insetos. $\mathrm{O}$ cultivo dessas plantas tem resultado em significativa redução de agroquímicos. A Argentina reduziu esses insumos em US\$ 500 milhões por ano, o mesmo ocorrendo em outros países. Huang \& Qiao (2000) relatam os resultados obtidos por 283 pequenos agricultores que cultivam algodão Bt (toxina de Bacillus thuringiensis) resistente a insetos. Houve sensível redução no uso de inseticidas, sem redução da qualidade da fibra, com substancial benefício econômico. Os agricultores relataram ainda menos acidentes com inseticidas em relação ao cultivo com algodão não-transgênico. Os agricultores são os mais afetados pelos agroquímicos. Nos anos de 1998-1999 foram registrados, no Paraná, 29,2 mil casos de intoxicação por agrotóxicos (OESP, 2001). A redução no uso de agroquímicos é também desejável para o meio ambiente e para o consumidor, embora os pesticidas naturalmente presentes nas plantas representam 99,99\% de todas as toxinas ingeridas na alimentação (Ames \& Gold, 1989). Produtos transgênicos estão sendo utilizados desde 1996 por milhões de consumidores, sem qualquer registro de dano à saúde ou ao meio ambiente. 
Inúmeros produtos transgênicos estão sendo pesquisados e novos estão em fases iniciais de obtenção. Caracteres de qualidade, como melhor qualidade de óleos comestíveis, de proteínas e de outros componentes estão em fase experimental. Um arroz mais rico em caroteno precursor de vitamina A e de ferro está disponível. As possibilidades oferecidas pela nova biotecnologia são praticamente ilimitadas. Isso não significa, entretanto, que todo o melhoramento de plantas será conduzido com essa tecnologia. O melhoramento convencional e a transgenia não são mutuamente excludentes, mas se complementam. A transgenia é mais uma ferramenta, como tantas outras desenvolvidas no passado, que deverá ser usada conjuntamente com as técnicas convencionais responsáveis pelos grandes progressos agrícolas, e que continuarão a contribuir para o melhoramento genético.

O Brasil preparou-se para a era dos transgênicos, ao aprovar a Lei 8974 de 5/1/1995 que estabelece normas para o uso das técnicas de engenharia genética e liberação no meio ambiente de organismos geneticamente modificados, em decorrência da qual o Decreto 1752 de 20/12/95 criou a Comissão Técnica Nacional de Biossegurança (CTNBio) com ampla representação da sociedade e de órgãos governamentais. Depois de muito trabalho e resoluções, tem havido contestações na área jurídica, resultando em restrições aos transgênicos, inclusive para fins experimentais. Paarlberg (2000) considera quatro possíveis políticas governamentais com relação aos transgênicos:

Promocional, quando os transgênicos são avaliados de maneira idêntica às novas cultivares obtidas anualmente pelos métodos convencionais, uma vez que são considerados essencialmente equivalentes. Tal é o caso, por exemplo, dos Estados Unidos e de países onde os transgênicos são sancionados com base na aprovação em outros países.

Permissiva, em que os transgênicos são avaliados caso a caso para riscos demonstrados, isto é, serão proibidos caso haja comprovação de que causam danos.

Precautória, na qual os transgênicos são também avaliados caso a caso para comprovação científica de que não causam danos. Como o princípio da precaução não estabelece limites, há o problema de que a certeza científica de risco igual a zero não existe, levando a uma restrição total e impedindo toda e qualquer inovação tecnológica.

Preventiva, em que os transgênicos não são avaliados caso a caso, e proibidos por serem considerados perigosos devido ao procedimento empregado em sua obtenção.

Fica evidente que órgãos específicos para análise de transgênicos só se justificam nos casos das políticas permissiva ou precautória. Paarlberg (2000) faz uma análise comparativa entre quatro países em desenvolvimento: Brasil, China, 
Índia e Kenya. A China tem uma política permissiva; a Índia e o Kenya, políticas precautórias; o Brasil, considerado também como tendo oficialmente uma política precautória, mantém na atualidade situação preventiva, objetivo de várias organizações empenhadas na proibição total de transgênicos.

\section{Agricultura empresarial e agricultura de subsistência}

Outra possível diferença existente entre países desenvolvidos, em geral nos climas temperados, e os chamados em desenvolvimento, que predominam nos trópicos, é a preponderância de uma agricultura empresarial naqueles, em comparação com uma extensa agricultura de subsistência nos últimos.

A agricultura empresarial, que também pode ser familial, caracteriza-se pelo emprego de alta tecnologia, eficiente uso de insumos, como adubações, irrigação, agroquímicos entre outros, visando à obtenção de alta produtividade por unidade de área e elevada eficiência.

Por outro lado, a agricultura de subsistência, em geral de natureza familial, é bem menos tecnificada, conta com poucas possibilidades do emprego de tecnologias mais avançadas, resultando em produtividade, em geral, sensivelmente mais baixa.

Ambas as modalidades têm sua importância social e econômica. A agricultura empresarial é a que abastece em maior quantidade os produtos requeridos pela população em geral, que é a mais numerosa, pois mais de $80 \%$ desse contingente dependem dos produtos agrícolas produzidos. Além disso, esse tipo de agricultura contribui de modo expressivo nas exportações, gerando divisas e tributos em geral. A agricultura de subsistência tem elevado apelo social, uma vez que significativa parcela dos agricultores depende dessa atividade para a sua sobrevivência

Face ao exposto, freqüentemente se discute se as pesquisas desenvolvidas por setores governamentais deveriam ser prioritariamente dirigidas a uma ou a outra dessas modalidades agrícolas. Por razões óbvias, o setor privado prioriza a agricultura empresarial, estando esta, em geral, bem atendida quanto às suas necessidades para a obtenção de elevados rendimentos agrícolas. Assim, parece indicado que o setor público dedique parte dos seus recursos destinados à pesquisa que melhor atende às necessidades de uma agricultura de subsistência. O setor público deveria desenvolver pesquisas de elevada tecnologia pelas seguintes razões: possibilitar a seus pesquisadores acompanharem os progressos científicos, sob pena de ficarem à margem dos avanços da ciência; deve também ter a possibilidade de oferecer alternativas à agricultura empresarial para que a mesma tenha mais opções e diminua sua dependência do setor privado; deve ainda viabilizar progressivamente a utilização, pela agricultura de subsistência, de tecnologias desenvolvidas que contribuam para a maior eficiência agrícola. 
A permanência indefinida de uma agricultura de subsistência corresponde à manutenção de uma situação de miséria permanente. $\mathrm{O}$ desejável é que esses agricultores consigam, com o tempo, galgar um patamar mais alto, que os aproxime de uma agricultura de elevada tecnologia, podendo, eventualmente, chegar a uma agricultura nos moldes empresariais. Para tanto, o cooperativismo ou associativismo é condição essencial: o pequeno deve se tornar grande.

\section{Necessidades e problemas}

As principais necessidades e os problemas mais relevantes inerentes à agricultura e à pesquisa cientifica podem ser considerados os seguintes:

- Estabelecimento de prioridades de pesquisas a serem conduzidas, levandose em consideração expectativas no curto, médio e longo prazos.

- Prioridade a apoio financeiro para projetos de pesquisa envolvendo uma verdadeira integração entre biotecnologia e programas de melhoramento genético. O Brasil conta hoje com recursos relativamente amplos para projetos de áreas consideradas de "ponta". Tal é o caso de programas que apoiam exclusivamente projetos de biotecnologia. Muito embora essa área deva merecer apoio, há necessidade de equilíbrio na disponibilização de recursos, sem a discriminação de projetos apenas por não conterem metodologias biotecnológicas. Está amplamente comprovado que os métodos convencionais de melhoramento são eficientes, ainda que a sua integração com a biotecnologia seja sempre desejável.

- Apoio à área de Engenharia Agrícola, que se encontra relativamente menos desenvolvida do que as demais áreas agrícolas.

- Estímulo a estudos climáticos, que possam conduzir ao melhor entendimento das variações e incertezas relativas aos climas tropicais, em particular os aspectos que afetam mais diretamente a agricultura.

- Estimulo a pesquisas relacionadas à Fisiologia Vegetal direcionadas à produtividade agrícola. Esta tem sido uma área relativamente menos desenvolvida, mesmo em países de Primeiro Mundo.

- Estabelecimento de política agrícola que estimule os agricultores a empregar tecnologias mais adequadas para aumentar a eficiência agrícola, dando-lhes assim condições para competirem no mercado internacional. Neste particular, seria desejável oferecer estímulos fiscais aos produtores rurais para que contratem engenheiros agrônomos e outros técnicos ligados à área, o que deverá refletir em aumentos de produtividade e de qualidade, beneficiando economicamente o país e a sociedade, além de ampliar as oportunidades de trabalho para os jovens egressos das faculdades. 
Referências bibliográficas

ABREU, A.F. de B.; RAMALHO, M.A.P.; SANTOS, J.B. \& MARTINS, L.A. Progresso do melhoramento genético do feijoeiro nas décadas de setenta e oitenta nas regiões Sul e alto Paranaíba em Minas Gerais. Pesquisa Agropecuária Brasileira, Brasília, n. 29, p. 105-112, 1994.

AMES, B.N. \& GOLD, L.S. Pesticides, risk, and applesauce. Science n. 244, p. 755$757,1989$.

ARAÚJO, J.S. de. Ganhos genéticos obtidos em híbridos e variedades de milho representando três décadas de melhoramento no Brasil. Lavras, 1995. Dissertação (mestrado), Universidade Federal de Lavras.

AVERY, D.T. Saving the planet with high-yield farming. ANNUAL CORN AND SORGHUM INDUSTRY RES. CONF, 49. Proceedings, 1994, p. 1-12.

BORLAUG, N.E. Human population, food demands and wildlife needs. NORTH AMERICAN WILDLIFE AND NATURAL RESOURCE CONFERENCE, 37, mimeo, 1972. $27 \mathrm{p}$.

Agricultura ecológica e a onda anti-tecnológica. SIMPÓSIO INTERNACIONAL SOBRE INTERAÇÕES SOLO-PLANTA EM CONDIÇÕES DE BAIXO pH, 4. Belo Horizonte, 17-24 de março de 1996.

CARVALHO, A \& FAZUOLI, L.C. Café. In: A.M.C. Furlani \& G.P. Viegas (eds.) O melhoramento de plantas no Instituto Agronômico de Campinas, 1993, p. 29-76.

EAST, E.M. Inbreeding in corn. Rept. Connecticut Agr. Exp. Sta. for 1907, p. 419$428,1908$.

EMBRAPA. Agricultura brasileira e pesquisa agropecuária. E. Paterniani (ed.), Brasília, Embrapa, 2000, 194 p.

FAO. Production yearbooks. Tables 1. Roma, 1969. . Production yearbooks. Tables 1. Roma, 1991.

Sustainable agricultural production: implications for international agricultural research. FAO Res. and Tech. Paper 4, 1989. 131 p.

FERREIRA, M. \& SANTOS, P.E.T. Melhoramento genético florestal dos Eucalyptus no Brasil: breve histórico e perspectivas. IN UFRO CONFERENCE ON SILVICULTURE AND IMPROVEMENT ON Eucalyptus. Salvador, Anais, Colombo: EMBRAPA/ CNPF 1, 1997, p.14-34.

FISHER, R. A. The correlation between relatives on the supposition of Mendelian inheritance. Trans. Roy. Soc. Edinb., n. 52, p. 399-433, 1918.

Boyd, 1936. Statistical methods for research workers, 6. ed. Londres, Oliver and 
FLOR, H.H. Host-parasite interaction in flax rust: its genetics and another implications. Phytopath, n. 45, p. 680-685, 1955.

HUANG, J \& QIAO, F. Impact of Bt cotton in China. INTERNATIONAL CONF. OF THE INTERNATIONAL CONSORTIUM ON AGRICULTURAL BIOTECHNOLOGY RESEARCH (ICABR) ON THE ECONOMICS OF AGRICULTURAL BIOTECHNOLOGY, 4. Ravello, Italia, 2000, p. 119-143.

JAMES, C. Global status of transgenic crops in 1997. ISAAA Briefs n. 5. Ithaca, N.Y., ISAAA, 1997. $31 \mathrm{p}$.

Y., ISAAA. 2001.

Global status of transgenic crops in 2000. ISAAA Briefs. Ithaca, $\mathrm{N}$.

KRATTIGER, A.F. The importance of ag-biotech to global prosperity. ISAAA Briefs n. 6. Ithaca, N.Y., ISAAA, 1998. 11 p.

MACEDO, N.; ARAÚJO, J.R. \& BOTELHO, P.S.M. Sixteen years of biological control of Diatraea saccharalis (Fabr.) (Lepidoptera: Pyralidae) by Cotesia flavipes (Cam.) (Hymenoptera: Braconidae), in the State of São Paulo. Anais da Soc. Entomológica do Brasil, v. 22, p. 441-448, 1993.

MALAVOLTA, E. Fertilizantes, corretivos e produtividade: mitos e fatos. REUNIÃO BRASILEIRA DE FERTILIDADE DO SOLO E NUTRIÇÃO DE PLANTAS, 20, 1997, p. 89-153, .

O ESTADO DE S. PAULO. Editorial, 14 jul. 2001.

PAARLBERG, R.L. Governing the GM crop revolution: policy choices for developing countries. International Food Policy Research Institute. Discussion Paper 33, 2000. $36 \mathrm{p}$.

PATERNIANI, E. Maize breeding in the tropics. Critical Reviews in Plant Sciences, $\mathrm{n}$. 9, p. 125-154, 1990.

RANGEL, P.H.N.; GUMARÃES, E.P. \& NEVES, P.C.F.N. Base genética das cultivares de arroz (Oryza sativa L.) irrigado no Brasil. Pesquisa Agropecuária Brasileira, Brasília, n. 31, p. 349-357, 1996.

SOARES, A.A. \& RAMALHO, M.A.P. Estimativas do progresso genético no melhoramento do arroz (Oryza sativa L.). Comparação de métodos. Ciência e Práticas, Lavras, n. 17, p. 27-34, 1993.

SHULL, G.H. A pure line method of corn breeding. Am. Breed. Assoc. Rept., n. 5, p. 51-59, 1909.

STORK, J. \& TEAGUE, W.D. Flour for man's bread. Minnesota, Univ. Minnesota Press, 1952. 382 p.

VENCOVSKY, R.; MORAES, A.R. GARCIA, J.C. \& TEIXEIRA, N.M. Progresso genético em 20 anos de melhoramento do milho no Brasil. CONGRESSO NACIONAL DE MILHO E SOJA. Belo Horizonte, Resumos, p. 300-307, 1986. 
RESUMO - A Agricultura sustentável deve envolver o manejo eficiente dos recursos disponíveis para satisfazer às crescentes aspirações de uma também crescente população, mantendo ou melhorando a qualidade do ambiente e conservando os recursos naturais. Tendo surgido há dez mil anos, a agricultura passou por várias fases, atingindo no presente uma eficiência sem precedentes graças ao emprego racional dos avanços científicos. A agricultura tropical enfrenta mais problemas, que são também mais complexos do que aqueles que ocorrem nos climas temperados. Apesar das limitações, o Brasil tem a agricultura tropical mais desenvolvida. Progressos subseqüentes são esperados com o emprego de técnicas inovadoras, como a Biotecnologia.

ABSTRACT - Sustainable agriculture should involve the successful management for resources to satisfy changing human needs while maintaining or enhancing the quality of the environment and conserving natural resources. Since ten thousands years ago agriculture developed to several phases, attaining at present an extraordinary efficiency, thanks to the employment of scientific advances. Tropical agriculture presents more problems of higher complexity in comparison to those of temperate climates. In spite of the limitations, tropical Brazilian agriculture is better developed regarding the tropical world in general. Promising new advances are expected from technical innovations, such as Biotechnology.

Ernesto Paterniani é professor da Escola Superior de Agricultura Luiz de Queiroz, USP-Piracicaba, SP.

O autor agradece ao professor Euripedes Malavolta pelas sugestões apresentadas. 


\section{APÊNDICE}

\section{In Balance With Nature}

In the beginning

John Carew

There was Earth, beautiful and wild;

And then came man to dwell.

At first, he lived like other animals

Feeding himself on creatures and plants around him,

And this was called IN BALANCE WITH NATURE.

Soon man multiplied.

He grew tired of ceaseless hunting for food;

He built homes and villages,

Wild plants and animals were domesticated.

Some men became Farmers so that others might become

Industrialists, Artists, Doctors, Lawyers or Bureaucrats

And this was called Society.

Man and Society progressed.

With his God-given ingenuity, man learned to feed, clothe, protect, and transport himself more efficiently so he might enjoy Life.

He built cars, houses on top of each other, and nylon.

And life was more enjoyable.

The men called Farmers became efficient.

A single farmer grew food for 41 Industrialists, Artists and doctors

And Writers, Engineers, and Teachers as well.

To protect his crops and animals, the Farmer produced

substances to repel or destroy Insects, Diseases and Weeds.

These were called Pesticides.

Similar substances were made by Doctors to protect humans.

These were called Medicine.

The Age of Science had arrived and with it came better diet and longer,

happier lives for more members of Society.

Soon it came to pass

That certain well-fed members of Society

Disapproved of the Farmer using Science.

They spoke harshly of his technique for feeding,

protecting and preserving plants and animals.

They deplored his upsetting the Balance of Nature;

They longed for the Good Old Days.

And this had emotional appeal to the rest of Society.

By this time Farmers had become so efficient, society

gave them e new title: Unimportant Minority.

Because Society could not ever imagine a shortage of food

Laws were passed abolishing Pesticides, Fertilizers, and Food Preservatives.

Insects, Diseases, and Weeds flourished.

Crops and animals died.

Food became scarce.

To survive, Lawyers, Bureaucrats, Industrialists, Artists

and Doctors were forced to grow their own food.

They were not very efficient.

People and governments fought wars to gain more agricultural land.

Millions of people were exterminated.

The remaining few lived like animals,

Feeding themselves on creatures and plants around them,

And this was called IN BALANCE WITH NATURE. 